\title{
DISCRIMINAÇÃO CONTRA CONSUMIDORES DE BAIXA RENDA
}

\section{DISCRIMINATION AGAINST LOW INCOME CONSUMERS}

Paula Oliveira do Espírito Santo

Aluna do Departamento de Administração da Pontifícia Universidade Católica do Rio de Janeiro

Rio de Janeiro, RJ, Brasil

E-mail: paula.oesanto@hotmail.com

Marcus Wilcox Hemais

Professor do Departamento de Administração da Pontifícia Universidade Católica do Rio de Janeiro

Rio de Janeiro, RJ, Brasil

E-mail: mhemais@gmail.com

\section{RESUMO}

Diferentes autores indicam que empresas dedicadas a vender a consumidores de baixa renda deveriam adaptar produtos e serviços para mais bem atendêlos. O que se percebe, entretanto, no Brasil, é uma realidade diferente. Isso ocorre porque empresas têm preconceito em atender esses consumidores, que se sentem discriminados em ambientes varejistas. $O$ presente estudo tem por objetivo explorar como ocorre e quais são as reações de consumidores de baixa renda que sofrem discriminação em ambientes varejistas. Com base em 18 entrevistas em profundidade, foi possível detectar elementos que diferenciam consumidores de baixa renda em ambientes varejistas, levando a sua discriminação. Apesar da discriminação, diferentes reações foram tomadas pelos entrevistados, para confrontar vendedores que os destrataram. A discriminação resulta em os entrevistados mudarem a forma de se relacionar com varejistas, para evitar nova discriminação. As conclusões discutem a visão romantizada da literatura de marketing sobre a relação entre consumidores de baixa renda e empresas.

Palavras-chave: Consumidor de baixa renda. Discriminação. Varejo. Vendedor. Base da pirâmide.

\section{ABSTRACT}

Different authors state the companies devoted to selling to low income consumers should adapt products and services to better serve them. In truth, this reality is different in Brazil. This happens because companies have prejudice against these consumers, whom feel discriminated in retail environments. The present study aims to explore how discrimination occurs in retail environments and what reactions low income consumers have. Based on 18 in depth interviews, it was possible to identify elements that differentiated low income consumers in retail environments resulting in their discrimination. Despite the discrimination, different reactions were taken by interviewees, to confront store clerks that mistreated them. Discrimination results in low income consumers changing the way they relate to retailers. It can be concluded, therefore, that marketing literature romanticizes the relationship between these consumers and companies, giving little attention to the fact that discrimination is a present reality that needs to be addressed.

Keywords: Low income consumer. Discrimination. Retail. Salesclerk. Base of the pyramid.

Data de aprovação: 24 de julho de 2016. 


\section{INTRODUÇÃO}

Desde que Prahalad proferiu sobre o potencial de consumo da base da pirâmide (BdP) global, no início dos anos 2000 (PRAHALAD; HART, 2002; PRAHALAD; HAMMOND, 2002), cresce o interesse da área de marketing em mais bem conhecer os comportamentos de consumidores de baixa renda (KOTLER; ROBERTO; LEISNER, 2006). A justificativa para isso está na argumentação de que existem quatro bilhões de indivíduos na BdP e que empresas interessadas em adaptar suas ofertas a atendê-los podem obter lucros significativos. Mais do que uma proposta financeira, entretanto, essa iniciativa pode ajudar o segmento a melhorar sua qualidade de vida, contribuindo, assim, para erradicar a pobreza (PRAHALAD, 2006).

Pesquisas em marketing passam, então, a ressaltar como ações empresariais voltadas para a BdP podem equacionar lucros e ajudar no combate à pobreza (BHARTI; SHARMA; AGRAWAL; SENGAR, 2014; SUBRAHMANYAN; GOMEZ-ARIAS, 2008), resultando em "bons sentimentos" por parte de consumidores de baixa renda direcionados a empresas, por estarem ajudando a solucionar esse problema mundial (WOOD; PITTA; FRANZAK, 2008). Tais sentimentos são derivados da felicidade desse segmento em ser respeitado, sem precisar provar sua honestidade (BARKI; PARENTE, 2010).

No Brasil, a busca por mais bem conhecer o comportamento do segmento de baixa renda também é percebida (MATTOSO; ROCHA, 2008; CHAUVEL; SUAREZ, 2009; ROCHA; ARAUJO; MOTTA, 2014). Tamanho interesse ocorre em função de o segmento representar um importante estrato econômico no país. Segundo dados da Secretaria de Assuntos Estratégicos (2012), o Brasil possui $80 \%$ de sua população distribuída entre as classes C, D e E, que representam quase 160 milhões de brasileiros. Somente a classe C possui um poder de compra de 1,03 trilhões de reais.

Diante dessa realidade, pode-se supor que o empresariado brasileiro adaptasse sua oferta, para mais bem atender consumidores de baixa renda. O que se percebe, entretanto, é que há poucas adaptações para se adequarem às realidades desse segmento (ZILBER; SILVA, 2013). Uma justificativa para isso pode ser a vergonha e o preconceito empresarial em atender esses consumidores (AGUIAR; TORRES; MEIRELES, 2008; SÁ, 2011; NEUMAN, 2014), o que leva, em consequência, à sua discriminação (CHAUVEL; MATTOS, 2008; CHAUVEL; SUAREZ, 2009; SALLES, 2011). Há entre o empresariado brasileiro uma "espécie de 'complexo de aristocracia', que leva nossos executivos a concentrarem seus interesses em produtos e serviços direcionados à alta classe" (PARENTE; BARKI, 2005, p.34).

A literatura sobre discriminação a consumidores indica que esse fenômeno ocorre quando minorias são distratadas em ambientes varejistas em função de sua etnia (BOSCH; $\mathrm{COBACHO}$, 2012), raça (HARRIS; HENDERSON; WILLIAMS, 2005), orientação sexual (WALSH, 2009) ou gênero (MORTON; ZETTELMEYER; SILVA-RISSO, 2003). Poucos estudos, entretanto, trazem discussões a partir do nível de renda do consumidor.

Embora essa seja a realidade da literatura de marketing atualmente, debates sobre discriminação a consumidores de baixa renda eram comuns nos primeiros estudos da área sobre a relação entre empresas e esse público. Diferentes autores apontavam haver exploração de vendedores "inescrupulosos" a esse público (ANDREASEN, 1975; STURDIVANT; WILHELM, 1969). Além disso, mostravam como era diferente o tratamento dado a consumidores de baixa renda de raças e etnias que fugiam às dominantes (STURDIVANT; HANSELMAN, 1971). Tais estudos, todavia, não se perpetuaram (ANDREASEN, 1978), e a lógica que 
determina a relação entre consumidores de baixa renda e empresas, atualmente, aproxima-se daquela descrita por Prahalad (2006).

A visão "romantizada" da literatura de marketing (KARNANI, 2011) sobre a relação entre empresas e consumidores de baixa renda deixa de lado discussões que apontam ser problemático esse relacionamento (CHAUVEL; SUAREZ, 2009; ROCHA, 2000). Assim, questões sobre discriminação são pouco elucidadas, embora a existência desse fenômeno ponha em cheque o quanto existem de "bons sentimentos" (WOOD; PITTA; FRANZAK, 2008) entre ambas as partes. Dessa forma, o presente estudo busca trazer luz sobre essa lacuna, ao explorar como ocorre e quais são as reações de consumidores de baixa renda que sofrem discriminação em ambientes varejistas.

O restante do artigo é dividido em mais quatro tópicos. No segundo, é apresentado o referencial teórico, que consiste em discussões sobre discriminação a consumidores em ambientes varejistas e a relação problemática entre consumidores de baixa renda e empresas. No terceiro, a metodologia empregada no estudo é descrita. No quarto, são analisados os dados coletados em 18 entrevistas em profundidade com consumidores de baixa renda. Por fim, na quinta, são feitas as considerações finais do estudo.

\section{REFERENCIAL TEÓRICO}

De maneira a apresentar a literatura pertinente ao tema estudado, o referencial teórico é dividido em dois subtópicos, que abordam, inicialmente, o fenômeno da discriminação a consumidores em ambientes varejistas e, em seguida, a relação problemática entre consumidores de baixa renda e empresas.

\section{Discriminação a consumidores em ambientes varejistas}

A discriminação contra consumidores é um tema com pouco destaque dentro da literatura de marketing (AINSCOUGH; MOTLEY, 2000). Todavia, apesar de escasso conhecimento dentro da área, o que se entende é que raça (HARRIS et al., 2005), etnia (BOSCH; COBACHO, 2012), gênero (MORTON; ZETTELMEYER; SILVA-RISSO, 2003), orientação sexual (WALSH; McGUIRE, 2007) e, até, maneira de se vestir (FITZPATRICK; FRIEND; COSTLEY, 2004) geram comportamentos discriminatórios dentro de ambientes varejistas.

Quanto a etnia e raça, manifestações discriminatórias em ambientes varejistas, nos Estados Unidos, ocorrem tanto para afrodescendentes quanto para hispânicos, asiáticos, nativos americanos e árabes. As principais formas como tais atos se desenvolvem são por degradação, negação de serviço ou tratamento com suspeitas (HARRIS; HENDERSON; WILLIAMS, 2005). Por esses consumidores apresentarem características visuais típicas de minorias, acabam sendo mais facilmente detectados e, em consequência, discriminados (AINSCOUGH; MOTLEY, 2000).

Mesmo quando características visuais conseguem ser "escondidas", como ocorre em compras pela internet, outro elemento conta para gerar a discriminação. Indivíduos que possuem nomes claramente identificados como sendo de outras nacionalidades, que não à do país onde a loja virtual se encontra, relatam diferenças na forma como são respondidos seus e-mails questionando sobre preços de determinados produtos (BOSCH; COBACHO, 2012). 
Alguns estudos debatem que o gênero também é determinante para haver discriminação. Por um lado, autores descrevem como mulheres sofrem atos discriminatórios, especialmente em ambientes varejistas que, historicamente, são associados a homens, tais como oficinas mecânicas (MORTON; ZETTELMEYER; SILVA-RISSO, 2003; WALSH, 2009). Por outro, quando estão em lojas de departamento, locais comumente frequentados por mulheres, tendem a vivenciar experiências de consumo mais positivas do que o público masculino (AINSCOUGH; MOTLEY, 2000).

Outro fator que fomenta discriminação em ambientes varejistas é a orientação sexual do consumidor. Gays e lésbicas percebem ser altamente discriminados quando buscam serviços que, tradicionalmente, seriam associados a heterossexuais, tais como abrir contas bancárias conjuntas ou obter quartos com camas de casal em hotéis. Nesse caso, a discriminação ocorreria porque o provedor de serviços se identifica com um grupo, e não deseja se "conectar" com outro que seja homossexual, expressando seu pensamento em forma de comportamento discriminatório (WALSH, 2009).

Além de características hereditárias e orientações sexuais, o vestuário do consumidor também leva à discriminação em ambientes varejistas (AINSCOUGH; MOTLEY, 2000; KIM; LENNON, 2005). Estudos mostram como o tempo para alguém mal vestido ser atendido é mais longo quando comparado ao de uma pessoa mais formalmente vestida. Além disso, a rapidez e a simpatia para atender um consumidor variam em função de sua vestimenta.

Pesquisas sobre discriminação tendem a olhar esse ato pela visão do consumidor. Walsh (2009), entretanto, busca uma explicação para esse fenômeno a partir de características de quem pratica a discriminação, o vendedor, apontando que seu perfil demográfico (idade, grau de escolaridade e gênero) e sua motivação interna (satisfação e grau de estresse com o emprego) e motivação externa (orientação para o consumidor e nível de scripts de serviços oferecidos pela empresa) seriam determinantes para a ocorrência desse fenômeno. Para o autor, vendedores mais jovens, do sexo feminino, satisfeitos e pouco estressados com seus empregos, que fossem orientados para o consumidor e possuíssem scripts para orientá-los sobre formas de atendimento seriam menos propensos a discriminar consumidores.

Após sofrerem atos discriminatórios, consumidores demonstram diferentes formas de reação: reclamam formalmente, sentem-se insatisfeitos, adotam boca-a-boca negativo, diminuem a lealdade e o grau de confiança com a empresa, ou ignoram a situação (WALSH; McGUIRE, 2007). Pessoas que relatam não reagir quando sofrem discriminação tendem a esse caminho para se protegerem contra os intensos sentimentos negativos que poderiam vir a sentir, como um afastamento psicológico do problema, não lembrando ou discutindo-o em detalhes, minimizando, assim, o ocorrido (CROCKETT; GRIER; WILLIAMS, 2003).

Apesar dos esforços em entender a discriminação a consumidores, ainda é confuso como isso ocorre quando manifesta contra aqueles de menor renda. Comumente, encontra-se o assunto vinculado a outros tipos de manifestações discriminatórias, em especial étnica e racial, o que gera imprecisão na distinção e definição dos diferentes conceitos. Talvez, por isso, exista uma precariedade de estudos que abordem a temática da discriminação com foco exclusivo no mercado de baixa renda. 


\section{Relação problemática entre consumidores de baixa renda e empresas}

Uma das principais preocupações que Prahalad (2006, p.20) alerta empresas interessadas em vender para consumidores de baixa renda é a necessidade de gerar confiança nesse público, pois, segundo o autor, esse sentimento "é difícil de construir depois de 50 anos de suspeitas e preconceitos". Apesar de tal ressalva, o autor pouco se aprofunda nessa questão, que parece ter sido esquecida frente aos argumentos de que esforços empresariais persistentes e a oferta de produtos e serviços de alta qualidade podem transpor quaisquer animosidades entre as partes.

Embora a literatura atual de marketing pouco discuta o fenômeno de discriminação contra consumidores de baixa renda (AINSCOUGH; MOTLEY, 2000), os primeiros estudos da área sobre esse público e sua relação com empresas, nos Estados Unidos, preocupavam-se com essa questão.

Considerado como um dos primeiros autores a estudar consumidores de baixa renda e seu comportamento de compra, Caplovitz (1967) argumenta que é desigual a relação de poder entre esse público e empresas, que se aproveitam de tal fato para cobrar preços exorbitantes, a altas taxas de juros, por produtos desnecessários e de baixa qualidade. Esses consumidores acabam pagando mais caro para consumir, porém obtêm menos valor em suas compras. Em função disso, dificilmente conseguem juntar dinheiro, para que melhorem suas vidas, ficando presos à pobreza.

Outros autores passaram a investigar a relação entre consumidores de baixa renda e empresas. Toyer (1968), por exemplo, relata que vendedores em bairros habitados por esse público elevavam o preço de suas mercadorias nos dias em que clientes recebiam seus rendimentos (check days). Consequentemente, estes consumidores perdiam poder de compra, o que afetava a quantidade de produtos que podiam adquirir. Mesmo se tentassem comprar produtos fora das épocas de preços elevados, dificilmente conseguiriam, pois seus parcos rendimentos mal os sustentavam até o próximo recebimento.

Diferentes estudos sobre a discriminação de preços de produtos vendidos a consumidores de baixa renda foram realizados nesta época. Enquanto alguns autores (DIXON; McLAUGHLIN, 1971) indicavam que não havia diferenças significativas de preços entre estabelecimentos em que estes indivíduos faziam compras, outros apontavam o oposto. Estudiosos dessa segunda corrente mostram que produtos comprados através de parcelamento, prática comum entre consumidores de baixa renda, produzem grandes variações de preços. Desta forma, estes indivíduos pagam mais por um produto que, em lojas fora de seus bairros, pagariam valores menores (STURDIVANT; WILHELM, 1969).

De acordo com Jones (1969), tais práticas abusivas contra consumidores de baixa renda foram a justificativa para o governo americano, por intermédio da Federal Trade Commission (FTC), criar um departamento específico para proteger consumidores de baixa renda daqueles que os "vitimizam". Seu papel é detectar práticas abusivas que se aproveitam dos "medos e falta de sofisticação" destes indivíduos, já que, por conta própria, não possuem meios ou confiança para apelar a recursos legais. De todas as responsabilidades da FTC, esta é a de maior importância, pois enfrenta:

As práticas dos vigaristas que se especializam em todo tipo de artimanha para induzir o pobre a suas portas, e coagi-los a fazerem compras indesejadas, que os deixam para sempre a mercê de seus devedores, com poucas esperanças de se desprender dos tentáculos da dívida em que se encontram (p.248). 
A responsabilidade governamental perante a fragilidade dos pobres também é discutida por Andreasen (1975), quando sugere que, para defender consumidores de baixa renda contra vendedores "inescrupulosos", é necessária a imposição mais rigorosa de leis municipais, estaduais e federais. Para isso, o autor defende mudanças nas legislações vigentes, permitindo que este segmento tenha melhores condições de se defender, e a criação de uma agência reguladora, para atender exclusivamente estes indivíduos.

Além de serem discriminados por sua baixa condição econômica, consumidores também recebiam tratamento discriminatório em ambientes varejistas em função de sua raça e etnia. Em geral, aqueles de baixa renda que eram afrodescentes ou de etnias latino-americanas recebiam atendimento de menor qualidade do que seus pares com níveis de renda mais elevada, brancos e de origem anglo-saxã (STURDIVANT; HANSELMAN, 1971). Todavia, quando os consumidores afrodescendentes e de etnias latino-americanas eram de classes de renda mais elevada, não foi percebida diferença em seu tratamento quando comparado à maneira como seus pares de raça branca eram tratados, reforçando o quanto a condição econômica do indivíduo é determinante para sua discriminação (GRIFFIN; STURDIVANT, 1973).

A justificativa dada por autores da época à existência da discriminação contra consumidores de baixa renda era a falta de educação e, consequente, fragilidade desse indivíduo diante de empresas (RATNER, 1968). Assim, acabavam por ser tratados com menos respeito, pois não se enquadravam em um perfil de público "atraente" (ANDREASEN, 1975).

Estudos sobre consumidores de baixa renda foram sendo deixados de lado no final dos anos 1970 (ANDREASEN, 1978), e pouco se pesquisou a respeito desse público renda até os trabalhos de Prahalad (PRAHALAD; HART, 2002; PRAHALAD; HAMMOND, 2002). Todavia, pesquisas que surgiram desde então pouco discutem esse lado problemático da relação entre empresas e o público em questão, debatendo, ao invés, que consumidores de baixa renda são tratados com zelo em ambientes varejistas (BARROS; ROCHA, 2009; WOOD; PITTA; FRANZAK, 2008).

\section{METODOLOGIA}

O pouco conhecimento sobre o comportamento de consumidores de baixa renda, no Brasil, tem resultado em estudos em marketing voltados para entender esse público serem desenvolvidos com finalidades exploratórias. Acabam por adotar, em diversos casos, metodologias qualitativas em sua coleta de dados (CHAUVEL; SUAREZ, 2009; MATTOSO; ROCHA, 2008), abordagem essa que também será adotada para o presente estudo.

A coleta de dados da pesquisa foi feita por meio de entrevistas em profundidade com 18 consumidores, escolhidos por acessibilidade, pertencentes às classes $C, D$ e $E$, e que tinham sofrido discriminação em ambientes varejistas. Limeira (2008) aponta que consumidores dessas classes sociais, com base na classificação da Fundação Getúlio Vargas, são considerados de baixa renda no Brasil. Dessa forma, foram entrevistados oito consumidores da classe $C$, sete da Classe $D$ e três da classe $E$.

Foi escolha dos autores delimitar os episódios discriminatórios a alguns tipos de varejistas, mais especificamente a lojas de departamento, sapatarias e lojas de roupas, de maneira a facilitar a comparação dos relatos dos entrevistados. Além disso, a escolha também se apoiou no fato de pesquisas mostrarem 
ocorrências de discriminações contra consumidores de baixa renda nesses varejistas (NEUMAN, 2014; SÁ, 2011; SALLES, 2011).

Para garantir que todos os entrevistados seguissem o perfil desejado, perguntava-se, antes de recrutar uma pessoa, se ela havia sofrido algum ato discriminatório no último ano (entre julho de 2013 e julho de 2014). Desejou-se delimitar esse período de tempo para que as lembranças ainda fossem claras na memória dos participantes. Um dos participantes, ao responder essa pergunta, indagou: "Que pobre não sofre com isso todo dia?!". Talvez em função dessa explicação, houve facilidade em recrutar consumidores para a pesquisa, pois diversos alegavam já ter vivenciado algum ato discriminatório recente em ambientes varejistas (em alguns casos, até mais do que um).

Buscou-se participantes para a pesquisa que apresentassem distintos perfis, de maneira a obter diferentes visões sobre o fenômeno estudado. Assim, foram entrevistados dez mulheres e oito homens, com idades entre 19 e 54 anos, moradores da cidade do Rio de Janeiro. Dos 18 entrevistados, 14 estavam empregados, em profissões que variavam desde empregadas domésticas e assistente administrativo a até professora de colégio e gerente de loja. Dos quatro desempregados, dois eram estudantes universitários e os outros estavam em busca de empregos fixos, pois viviam de "bicos".

As entrevistas foram conduzidas a partir de um roteiro (pré-testado com dois consumidores de baixa renda), composto de perguntas abertas, baseadas na revisão de literatura. Em função de o roteiro seguir a configuração do tipo semiestruturado, isso permitia aos entrevistadores, quando necessário, elaborar outras perguntas, para obter mais detalhes dos participantes sobre assuntos importantes surgidos durante as entrevistas, mas que, de antemão, não se havia conhecimento a respeito.

A análise dos dados foi realizada em duas etapas. $\mathrm{Na}$ primeira, as transcrições do áudio das entrevistas foram codificadas, utilizando o programa Atlas/ti versão 7. Seguindo recomendações de Rubin e Rubin (2005), alguns dos códigos foram estabelecidos a partir da literatura, enquanto outros surgiram de fatos identificados nos relatos. Essa etapa foi importante para organizar os dados e determinar o momento quando foi alcançada a saturação dos dados. A partir do momento em que novos códigos não surgiam dos dados coletados, foram encerradas as entrevistas (GUEST; BUNCE; JOHNSON, 2006).

$\mathrm{Na}$ segunda etapa da análise dos dados, os relatos dos entrevistados foram comparados entre si e com o referencial teórico (ANFARA; BROWN; MANGIONE, 2002; GUMMESSON, 2005), de forma a encontrar semelhanças e diferenças no que era discutido. A partir de tal exercício, foi possível chegar às categorias de análise do estudo.

\section{ANÁLISE DOS DADOS}

A facilidade em encontrar consumidores de baixa renda que haviam vivenciado situações de discriminação contrasta com a pouca informação encontrada na literatura de marketing. A coleta de dados gerou ricos depoimentos, sendo possível entender os fatores que são percebidos pelos entrevistados como motivadores para sofrerem discriminação, suas reações após o ato discriminatório e como isso afetou sua relação com as empresas. 


\section{Elementos que levam à discriminação}

A partir dos relatos dos entrevistados, é possível entender que a discriminação contra consumidores de baixa renda em ambientes varejistas resulta, principalmente, de sua vestimenta, linguajar verbal e corporal e forma de pagamento. Era a partir desses elementos que vendedores detectavam que o consumidor era de uma classe socioeconômica inferior, e que, por isso, não pertencia àquele ambiente ou merecia atendimento adequado.

O vestuário foi o fator mais mencionado pelos entrevistados como motivador para a discriminação. Justificam esse pensamento porque "a roupa diz muito", como se existisse um código de vestimenta para consumir em determinados locais e que, naquele momento, não estavam seguindo-o. Usar shorts, chinelo e camiseta é estar "mal vestida" para entrar em uma loja de departamentos. Para que um indivíduo de mais baixa renda seja visto como um potencial consumidor, deve estar "super bem vestido", pois, assim, vivencia um tratamento "a pão de ló".

Para os entrevistados, a forma como se vestem evidencia que pertencem a uma classe socioeconômica inferior, que, em muitos casos, "não está dentro do perfil da loja". Assim, usar roupas associadas a um perfil de indivíduo de mais baixa renda é denunciar algo negativo quando se deseja consumir produtos de determinados ambientes varejistas. Somente vestido de maneira mais "arrumadinho", parecendo "riquinho", é que a tarja de "pobre" é deixada de lado e o tratamento recebido é tão bom quanto o de indivíduos de mais alta renda.

Tais questões vêm ratificar estudos (AINSCOUGH; MOTLEY, 2000; FITZPATRICK; FRIEND; COSTLEY, 2004; KIM; LENNON, 2005) que encontram evidências de que o vestuário do consumidor no momento da compra pode gerar percepções positivas ou negativas de vendedores sobre o mesmo. Além da aparência da roupa (velha, suja ou amarrotada), o fato de não ser "de marca" (em referência a produtos de qualidade superior) e/ou cara já é suficiente para gerar comportamentos discriminatórios, por evidenciar que o consumidor é de uma classe inferior.

O linguajar verbal e corporal do cliente no momento da compra também foi citado pelos entrevistados. O uso de gírias e trejeitos ao falar, incomuns a pessoas de classes de renda mais altas, evidencia que o consumidor "não pertence àquele ambiente". Em um primeiro momento, esse elemento não é detectado quando o consumidor entra sozinho em uma loja varejista, especialmente se está usando roupas condizentes com um perfil de consumidores de maiores níveis de renda. Mas, conforme aponta uma entrevistada, "o corpo fala", e logo o "disfarce" cai quando o consumidor começa a interagir com vendedores. No momento em que falam com um tom de voz mais alto, usam chavões populares ou gesticulam ao conversar, "fica claro" que são de segmentos de baixa renda. O atendimento que, até então, era indiferente ou "educado" muda, resultando em repreensão ao linguajar por meio da discriminação.

Poder-se-ia supor que tais discriminações ocorressem em função de consumidores de baixa renda frequentarem lojas varejistas voltadas para classes mais elevadas, com vendedores cujas origens também são da elite. Todavia, atos discriminatórios ocorriam tanto nesses ambientes quanto naqueles "mais populares". Enquanto que nos primeiros vendedores discriminavam consumidores que se vestiam ou falavam como um "peixe fora d'água", nos segundo a discriminação se dava em razão de vendedores facilmente 
saberem detectar quem eram consumidores de baixa renda, pois os próprios também eram desse segmento, vestindo-se e falando da mesma forma que suas "vítimas".

Esse achado complementa o estudo de Walsh e McGuire (2007), pois, embora os autores reconheçam que características demográficas de vendedores influenciam em sua conduta discriminatória, não discutem se a semelhança de idade, renda, grau de escolaridade, por exemplo, entre esses profissionais e consumidores afetam seu comportamento.

Outro elemento mencionado como determinante para a discriminação em ambientes varejistas é a forma de pagamento adotada pelo consumidor de baixa renda. Os entrevistados apontam que, comumente, utilizam cartões de crédito ("pra pagar em parcelas") ou crediário em suas compras - prática comum dentro do segmento pois, por meio desses serviços, conseguem adquirir produtos que, em épocas passadas, não possuíam e que, de outra forma, dificilmente teriam possibilidades de obtê-los (MATTOSO; ROCHA, 2008). Mas, ao fazê-lo, mostram que não possuem condições financeiras de pagar por algo à vista e, por isso, sentem que varejistas os discriminam.

Utilizar formas de pagamento por crédito, parcelando compras, acaba se tornando uma atividade vexatória para alguns consumidores de baixa renda, em função da diferença de tratamento que recebem de vendedores. Diversos entrevistados relatam desconforto em perguntar em ambientes varejistas se suas compras poderiam ser pagas em parcelas, pois sentiam tons preconceituosos de funcionários quando, por exemplo, respondiam: "Até pode 'né'? Fazer o quê?".

Essa "dependência" de consumidores de baixa renda em serviços de crédito como "única forma" para consumir bens desejados levou alguns entrevistados a pensarem que empresas dificultam pagamento por crédito, como alternativa para afastá-los de lojas. Uma entrevistada relata que, quando foi comprar uma camisa "de marca", foi avisada por uma vendedora que o produto "custa $\mathrm{R} \$ 250,00$, e a loja não aceita cartão de crédito".

Em resposta à discriminação, os entrevistados descrevem diferentes reações adotadas e sentimentos sofridos. Embora os fatores que levem aos atos discriminatórios sejam similares entre os relatos coletados, cada experiência parece única, marcante, resultando em distintas maneiras de lidar com o ocorrido, conforme é discutido no próximo subtópico.

\section{Reações após a discriminação}

As reações adotadas por consumidores quando sofrem atos discriminatórios em ambientes varejistas podem variar entre ignorar a situação, reclamar formalmente, diminuir a satisfação, adotar boca-a-boca negativo, diminuir a lealdade e diminuir a confiança na empresa (WALSH; McGUIRE, 2007). As reações relatadas pelos entrevistados após suas experiências seguem essa linha, mas, vale destacar que, mesmo vivenciando situações negativas, a maioria afirmou que a discriminação não foi suficiente para desmotivá-los a adquirir o produto que inicialmente os levou até a loja.

Em alguns casos, a compra do produto ganhou um significado maior do que somente à de adquirir algo desejado. Passou a ser encarada pelos entrevistados como uma forma de afronta aos vendedores que os discriminaram ("compro só de raiva"), mostrando que o consumidor era merecedor de consumir naquele estabelecimento. Uma entrevistada afirmou ter se sentido tão incomodada com a falta de atendimento dos 
vendedores - "Fingiram que eu não existia na loja" - que comprou a roupa mais cara disponível. Ela completa dizendo: "Não era a mais bonita, ou a que eu queria levar, mas comprei por orgulho".

Devido à sua renda ser limitada, "contada", esses consumidores dependem de serviços públicos precários, tais como transporte, saneamento e saúde. Dificilmente podem pagar para ter esses correspondentes do setor privado. Mas, quando se trata de bens menos dispendiosos, que "caibam na parcela", estão dispostos, até, a pagar mais por eles. Assim, privá-los do consumo é ferir seu orgulho; é tirar deles "um direito" que acreditam ter de, também, ter "mimos", "desejos" e "sonhos", assim como seus pares de mais alta renda. Por não entenderem o motivo para sofrerem a discriminação, já que ser da baixa renda "não tem nada de errado", passam a ver a discriminação como algo pessoal, que coloca em dúvida seu caráter, o que resulta em agudos sentimentos negativos direcionados ao vendedor e a empresa.

Comumente, a reclamação direta a vendedores ou gerentes de lojas era a forma utilizada pelos entrevistados para buscar retratação à discriminação. Um deles afirma ter exigido um pedido de desculpas dos vendedores, que pareciam atender outros clientes vestidos de forma mais elaborada, enquanto marginalizaram-no por suas vestimentas simples:

Disse (ao gerente da loja) que achava um absurdo! Os seus vendedores são muito mal educados. Eu acho um absurdo eu ficar procurando por um vendedor e todos eles olharem pra mim e fingirem que não me veem. Eles (em referência aos outros clientes na loja no momento) eram iguais a mim. Não sou diferente para não ter direito de comprar lá. Não entendi esse comportamento.

Houve, ainda, quem afirmasse ter feito boca-a-boca negativo da empresa para amigos e parentes. Todavia, quando indagados quanto a uma posterior reclamação formal à empresa ou sobre buscar ajuda de órgãos de proteção ao consumidor, somente dois dos entrevistados afirmaram terem contatado a empresa para reportar o caso. Nenhum entrevistado procurou meios legais de compensação. Um deles informou ter reportado a situação vivida por e-mail, pois "na hora, queria a demissão da menina". Para este, a empresa enviou uma resposta lamentando o episódio, oferecendo-o um vale-compra em qualquer loja da marca, como compensação pelo ocorrido. Mesmo assim, o pedido de desculpas não minimizou sua insatisfação com o mau atendimento. No outro caso, uma entrevistada afirma ter ligado, no mesmo momento, para o telefone de atendimento ao cliente da empresa. Neste canal, afirma ter sido orientada a entrar em contato por e-mail, mas, por meio deste, não recebeu resposta.

Apesar de não terem buscado ajuda legal, os entrevistados afirmaram que é válida a busca pelos direitos violados, pois acreditam que qualquer tipo de manifestação que combata a discriminação deva ser incentivada, para que haja melhoria no atendimento ao consumidor. Pensamento similar também é apontado por Chauvel e Suarez (2009), quando dizem que consumidores são favoráveis à intervenção de órgãos de defesa do consumidor, embora poucos dispendam esforços para ir a tais extremos de reclamação.

Os entrevistados que confessaram não buscar meios de retratação formal ou melhoria da situação parecem ter assim agido em razão de uma descrença quanto a um retorno real, que valesse o esforço, duvidando que varejistas mudem seu comportamento a esses consumidores. Relataram que o investimento de tempo e o "estresse de correr atrás disso" seriam grandes demais. Uma explicação para isso pode ser porque, em situações insatisfatórias de consumo, consumidores de baixa renda preferem não enfrentar empresas, por acharem que ninguém os dará ouvidos, terem receios de serem interpretados como 
"malandros", aproveitando-se da situação para obter benefícios facilmente, e acreditarem que, no fundo, são eles os culpados por tal situação (CHAUVEL; SUAREZ, 2009).

Contudo, a principal motivação apontada para a não reclamação foi o desconhecimento dos seus direitos ou do que deveria ser feito, conforme aponta uma entrevistada:

Eu não fiz porque eu não tinha essa consciência. Mas, hoje em dia, eu tenho. Se fosse hoje em dia, eu teria feito um escândalo maior, comentado com o gerente, colocado no Facebook, mandado chamar a polícia ou alguma coisa do tipo.

Poucos consumidores de baixa renda têm plenos conhecimentos dos seus direitos. A falta de consciência legal talvez seja um dos fatores que levem este segmento a recorrer à justiça apenas como uma das últimas alternativas, embora exista um aparato jurídico à sua disposição. Mas, em geral, seu pensamento é pessimista quanto a esse processo. Conforme afirma um entrevistado: "Seria eu contra a empresa, não tinha testemunhas. Acho que não daria em solução. Quem me garante que ele (o vendedor) não faria de novo com outra pessoa".

Se, por um lado, reclamações formais a empresas e busca de ajuda jurídica parecem distantes da realidade de consumidores de baixa renda, por outro, o uso de redes sociais como instrumento de reivindicação e protesto parece ser algo mais acessível. A facilidade de acesso e a possibilidade de não enfrentar "ao vivo" uma empresa fazem dessas mídias canais bastante utilizados pelos entrevistados. Acreditam que, por meio dessas, podem se vingar das empresas que os discriminaram ao "sujar a imagem delas" perante a sociedade, e, assim, reduzir a quantidade de consumidores interessados em se tornarem clientes.

Além de reações externas, os entrevistados relatam sentimentos que surgiram no momento em que se viram discriminados: "raiva", "dor", "chateação" e "tristeza". Outros, ainda, relataram sentimento de inferioridade: "Me senti um lixo. Ninguém vinha me atender, e, ainda, ficou com aquela cara de nojo (referindose ao vendedor que não ofereceu atendimento e em seguida, ao atender a cliente, pareceu estar insatisfeito em ter que fazê-lo)", afirmou uma entrevistada. Em um caso relatado, a tristeza era tamanha com a discriminação, que levou a entrevistada às lágrimas:

Eu me senti lesada, porque eu estava com dinheiro para comprar ali. Eu trabalhei dois dias aplicando prova. Aí, eu falei: 'Caraca! Vou comprar minha sandália à vista!'. Poxa, foi o meu suor, foi o meu salário. Eu me senti muito péssima, super desvalorizada. Eu fiquei mais triste do que com raiva.

Tais sentimentos foram ainda mais agudos quando a discriminação foi feita em frente a outros consumidores. Além de raiva e tristeza, os entrevistados precisaram lidar com o constrangimento, pois percebiam que, além dos vendedores, outras pessoas também os julgavam. A presença de demais consumidores em um ambiente varejista tende a afetar a forma como indivíduos reagem diante de situações insatisfatórias de consumo, normalmente fazendo com que uma experiência negativa seja sentida mais intensamente por quem a sofreu (YAN; LOTZ, 2009).

Como forma de evitar lembrar o constrangimento, alguns entrevistados minimizaram seus sentimentos negativos relativos à discriminação, demonstrando, por vezes, indiferença quanto à situação vivida. Essa reação pode ser explicada pelo fato de que é comum consumidores que vivenciam manifestações 
discriminatórias afastarem-se psicologicamente de seus sentimentos, como uma forma de proteção contra a dura realidade do problema (CROCKETT; GRIER; WILLIAMS, 2003). Todavia, apesar de agirem dessa forma, acabavam, por vezes em seus relatos, demonstrarem fortes sentimentos negativos em relação à empresa, como se o episódio discriminatório fosse algo importante a eles.

A partir de suas experiências negativas, os entrevistados relatam que mudaram a forma como percebem sua relação com empresas. Agora, são mais atentos e evitam potenciais situações que podem Ihes trazer novos episódios de discriminação, conforme é discutido no próximo subtópico.

\section{Mudanças de comportamento em relação a empresas}

Mesmo apresentando fortes sentimentos negativos, os entrevistados relatam diferentes posturas quanto a retornar à loja e/ou posterior compra, após terem sido discriminados. Enquanto alguns não viam problemas em voltar a fazer compras no estabelecimento, caso apresentasse algum produto que lhes agradasse, outros condenavam a ideia. Uma entrevistada, entretanto, viu-se em uma situação desconfortável, pois é dependente de um produto, para sua saúde, que somente é vendido no local em que foi discriminada. Assim, precisa continuar a comprar da empresa, mas evita ir à loja. Agora, faz suas compras online: "só volto na loja para trocar ou para comprar quando não tenha no site".

Em casos em que a relação com o produto é de grande envolvimento, a experiência discriminatória não é suficiente para afastar o consumidor de vez da loja. Por outro lado, quando o envolvimento com a marca é menor, por vezes a primeira compra, o retorno à loja é menos aceito entre os respondentes. Contudo, todos os entrevistados relataram que houve alguma mudança, em variados graus, quanto à forma como se relacionam com o consumo, depois do episódio de discriminação.

A partir de uma experiência negativa, os entrevistados passam a ver todas as lojas, especialmente aquelas cuja ambientação e preços sugiram ser voltadas para consumidores de mais alta renda, como locais propícios para serem discriminados. Para eles, a discriminação não é um ato exclusivo, que ocorre raramente. É algo constante se o indivíduo é de baixa renda e busca consumir em locais que não possuem diretrizes para atendê-los. Acreditam que sempre estão "deslocados" quando frequentam estabelecimentos "dos ricos", e que, a qualquer momento, podem ser discriminados, conforme relata uma entrevistada:

Tem loja que eu evito entrar. Ah, pra quê? Pra ser discriminada? Por exemplo, eu nunca entrei na (nome de loja varejista de roupas). Não faço a menor ideia de como é lá dentro. Eu sei que não vão me atender, que eu não vou ser bem atendida. Aí, eu sempre vou nas mesmas (lojas de departamento).

Uma explicação para esse pensamento por parte dos entrevistados é encontrada em diferentes estudos (ANDREASEN, 1975; BARKI; PARENTE, 2010, JONES, 1969) Os referidos autores afirmam que há desconfiança por parte de consumidores de mais baixa renda em comprarem de grandes empresas porque acreditam que estas exploram o fato de eles serem indivíduos com baixos níveis de autoestima e escolaridade, consequentemente tratando-os com menos respeito.

A maior mudança relatada pelos entrevistados foi na forma como se comportam diante de vendedores. Em função de esses profissionais serem vistos como a principal figura causadora da discriminação, maior cuidado com o relacionamento desenvolvido com eles passou a ser adotado pelos 
consumidores. Um dos entrevistados, por exemplo, contou que passou a reparar no atendimento dado a outros clientes e na feição de vendedores, antes de entrar em estabelecimentos comerciais. Outra entrevistada, por sua vez, afirma ter se tornado menos calorosa com vendedores: "Sou fria. Falo o que eu quero e só. Pá, pum. Acabou!". Dessa forma não se sente ofendida se o atendimento for abaixo de suas expectativas e evita, assim, parecer ser frágil, já que, para a entrevistada, pessoas com essas características seriam mais propensas a sofrer discriminação.

Alguns entrevistados chegam a creditar o comportamento discriminatório de vendedores como uma falha da empresa em treiná-los adequadamente, para que não haja variação na forma como atendem consumidores, independentemente de sua classe econômica. Eles não enxergam que a discriminação seja uma orientação empresarial, "até porque isso seria um crime". Mas, acreditam que, quando há manifestações discriminatórias, lojas tendem a "colocar panos quentes para abafar" sua ocorrência.

Apesar de não culparem a empresa pelo ocorrido, os entrevistados reconhecem que mudou a imagem que tinham do estabelecimento comercial. A discriminação é muito marcante para eles, de forma que não gostam de voltar ao local onde a experiência foi vivida ou, possivelmente, ter que rever o vendedor "agressor", já que isso os faria lembrar do episódio e a raiva e tristeza sentidas. Assim, levam seu "dinheiro suado" para outro local, às vezes sequer anunciando para a empresa sobre o motivo de estarem agindo dessa forma.

\section{CONSIDERAÇÕES FINAIS}

O presente estudo buscou trazer luz sobre como ocorre e quais as reações de consumidores de baixa renda que sofrem discriminação em ambientes varejistas. Para isso, realizou entrevistas em profundidade com indivíduos desse segmento, descobrindo os elementos que levam à sua discriminação, reações à situação discriminatória e como isso afetou sua relação com empresas.

A partir dos resultados, percebe-se que a discriminação a consumidores de baixa renda é mais comum do que a literatura de marketing demonstra (embora o assunto seja mais abertamente discutido em outras áreas de conhecimento, tais como psicologia e sociologia). A pouca discussão dentro de marketing contrasta com dados de pesquisas que falam sobre empresários com preconceitos contra esse público, além da percepção de consumidores de que são desrespeitados por vendedores, seja por sua vestimenta, linguagem ou forma de pagamento.

Uma explicação para o motivo de a literatura de marketing pouco discutir a discriminação é porque esse fenômeno ocorre, em maior frequência, com minorias, e, até pouco tempo, discussões sobre consumidores de baixa renda eram escassas na área, salvo aquelas realizadas entre 1960 e 1970, nos Estados Unidos. Em parte, isso pode ser atribuído à ótica "romantizada" que marketing adotou a respeito do assunto (KARNANI, 2011), após os artigos de Prahalad, assumindo que pode haver harmonia entre consumidores de baixa renda e empresas, já que interesses mútuos seriam atendidos; no caso, melhorias na qualidade de vida para os primeiros e lucros para os segundos. Essa linha de pensamento, entretanto, não reconhece que existe uma hierarquização de poder entre as partes (CHAUVEL; SUAREZ, 2009; ROCHA, 2000), que dificilmente será extinta.

Considerando-se que cada vez mais consumidores da classe $C$ tentam imitar, em termos de consumo, os das classes A e B (NERI, 2010), é coerente imaginar que esse público também queira comprar nos 
estabelecimentos comerciais que seus pares de renda mais afluente consomem. A falta de conhecimento sobre os valores que consumidores de baixa renda dão ao consumo não permite que se perceba o quanto valorizam a cultura material (BARROS; ROCHA, 2009). Gerar discriminação é um passo no sentido contrário ao que esses consumidores desejam e é incoerente com a ideia de que o consumo é inclusivo (PRAHALAD, 2006).

Embora vendedores sejam vistos como responsáveis pelos atos de discriminação, são os estabelecimentos comerciais que sofrem, pois perdem vendas e ficam com imagens manchadas. O problema mais grave, entretanto, é o fato de que a discriminação é uma infração da lei. Melhores orientações a esses profissionais sobre a conduta a assumir com consumidores, independentemente de sua classe, devem ser empregadas, de maneira a evitar que quaisquer manifestações desse tipo voltem a ocorrer.

Além de varejistas, a pesquisa também traz implicações relevantes para governos, pois evidencia que a discriminação é algo comum na vida de consumidores de baixa renda. A fiscalização mais cuidadosa a empresas que desrespeitem seus consumidores, somente porque não são de classes de maior renda, fazse, então, necessária. $O$ fato de órgãos de defesa do consumidor não terem sido acionados para retratar o ocorrido é preocupante, pois demonstra que ou esses consumidores não sabem que podem recorrer a essas instituições para resolver tais problemas ou que há descrença quanto aos benefícios que fazer uma reclamação a tais órgãos pode trazer. Assim, é sugerido que maiores esforços sejam realizados com o objetivo de educar esse público a respeito da função dos órgãos, ajudando, consequentemente, a haver maior fiscalização e repressão à discriminação em ambientes varejistas.

De maneira a continuar a linha de estudo proposta aqui, futuros estudos podem pesquisar qual é a visão de empresas varejistas a respeito dos consumidores do segmento em questão. Dessa forma, seria possível corroborar ou ratificar a percepção desse público a respeito de sua discriminação em ambientes varejistas e se tais atos ocorrem por iniciativas de vendedores ou orientações empresariais.

O presente estudo somente delimitou o episódio de discriminação a três tipos de empresas varejistas. Futuros estudos, portanto, poderiam considerar outras delimitações, de forma a entender as especificidades da discriminação contra consumidores de baixa renda em diferentes estabelecimentos varejistas.

Uma vez que tal estudo encontrou indícios da existência de consumidores de baixa renda que evitam entrar em determinados estabelecimentos comercias que praticam preços mais elevados ou cuja ambientação seja mais elaborada, também se torna importante pesquisar quais fatores influenciam na escolha destes indivíduos por determinada loja ou ponto de venda, em especial no que tange a questões não objetivas ou racionais. Alguns estudos já vêm sendo desenvolvidos nesse sentido (BARKI; PARENTE, 2010; SUTTER; PLUTARCO; PARENTE, 2013), tornando necessários outros para mais bem desvendar essa questão. 


\section{REFERÊNCIAS}

AGUIAR, L.; TORRES, H.; MEIRELES, R. O consumidor de baixa renda. In: PARENTE, J.; LIMEIRA, T.; BARKI, E. Varejo para a baixa renda, Porto Alegre: Bookman, 2008.

AINSCOUGH, T.; MOTLER, C. Will you help me please? The effects of race, gender and manner of dress on retail service. Marketing Letters, v.11, n.2, p.129-136, 2000.

ANDREASEN, A. The disadvantaged consumer. New York: The Free Press, 1975.

ANDREASEN, A. The ghetto marketing life cycle: a case of underachievement. Journal of Marketing Research, v.15, n.1, p.20-28, 1978.

ANFARA, V.; BROWN, K.; MANGIONE, T. Qualitative analysis on stage: making the research process more public. Educational Researcher, v.31, n.7, p.28-38, 2002.

BARKI, E.; PARENTE, J. Consumer behavior of the base of the pyramid marketing in Brazil. Greener Management International, v.56, p.11-23, 2010.

BARROS, C.; ROCHA, E. Lógica de consumo em um grupo das camadas populares: uma visão antropológica de significados culturais, In: ROCHA, A.; SILVA, J.F. Consumo na base da pirâmide - Estudos brasileiros. Rio de Janeiro: Mauad, 2009.

BHARTI, K.; SHARMA, V.; AGRAWAL, R.; SENGAR, A. Marketer's mindset: Key to develop bottom of the pyramid market. Procedia - Social and Behavioral Sciences, v.133, n.15, p.169-179, 2014.

$\mathrm{BOSCH}, \mathrm{M}$; $\mathrm{COBACHI}, \mathrm{M.B}$. Discrimination in second-hand consumer markets: evidence from a field experiment. Applied Economic Letters, v.19, n.17, p.1727-1730, 2012.

CAPLOVITZ, D. The poor pay more. New York: Free Press, 1967.

CHAUVEL, M.A.; MATTOS, M. Consumidores de baixa renda: uma revisão dos achados de estudos feitos no Brasil. Cadernos Ebape, v.6, n.2, p.1-17, 2008.

CHAUVEL, M. A.; SUAREZ, M. Consumidores Pobres e Insatisfação Pós-Compra: "Eles não Têm Respeito Pela Gente". In: ROCHA, A.; SILVA, J.F. Consumo na base da pirâmide - Estudos brasileiros. Rio de Janeiro: Mauad, 2009.

CROCKETT, D.; GRIER, S.; WILLIAMS, J. Coping with marketplace discrimination. Academy of Marketing Science Review, v.2003, n.4, p.1-18, 2003.

DIXON, D.; MCLAUGHLIN, D. Shopping behavior, expenditure patterns, and inner-city food prices. Journal of Marketing Research, v.8, n.1, p.96-99, 1971.

FITZPATRICK, M.; FRIEND, L.; COSTLEY, C. Dissatisfaction and distrust. Journal of Consumer Satisfaction, Dissatisfaction and Complaining Behavior, v.17, p.117-129, 2004.

GRIFFIN, W.; STURDIVANT, F. Discrimination and middle class minority consumers. Journal of Marketing, v.37, n.3, p.65-68, 1973.

GUEST, G.; BUNCE, A.; JOHNSON, L. How many interviews are enough?: An experiment with data saturation and variability. Field Methods, v.18, n.1, p.59-82, 2006.

GUMMESSON, E. Qualitative research in marketing - road-map for a wilderness of complexity and unpredictability. European Journal of Marketing, v.39, n.3/4, p.309-327, 2005.

HARRIS, A.; HENDERSON, G.; WILLIAMS, J. Courting customers: assessing consumer racial profiling and other marketplace discrimination. Journal of Public Policy \& Marketing, v.24, n.1, p.163-171, 2005.

JONES, M. Deception in the marketplace of the poor: the role of the Federal Trade Commission. In: STURDIVANT, F. (ed.). The ghetto marketplace. New York: Free Press, 1969.

KARNANI, A. Fighting poverty together: rethinking strategies for Business, Governments, and Civil Society to reduce poverty. New York: Palgrave Macmillan, 2011.

KIM, M.; LENNON, S. The effects of customers' dress on sales-person's service in large-sized clothing specialty stores. Clothing \& Textile Research Journal, v.23, n.2, p.78-87, 2005.

KOTLER, P.; ROBERTO, N.; LEISNER, T. Alleviating poverty: a macro/micro marketing perspective. Journal of Macromarketing, v.26, n.2, p.233-239, 2006.

LIMEIRA, T. O potencial do mercado de baixa renda. In: PARENTE, J.; LIMEIRA, T.; BARKI, E. Varejo para a baixa renda, Porto Alegre: Bookman, 2008.

MATTOSO, C.; ROCHA, A. Building, losing and reconstructing social identities: an investigation into the symbolic use of credit by poor consumers in Brazil. Latin American Business Review, v.9, n.3/4, p.227-255, 2008. 
MORTON, F.; ZETTELMEYER, F.; SILVA-RISSO, J. Consumer Information and Discrimination: Does the Internet Affect the Pricing of New Cars to Women and Minorities? Quantitative Marketing and Economics, v.1, p.65-92, 2003.

NERI, M. (Coord.) A nova classe média: o lado brilhante dos pobres. Rio de Janeiro: FGV/IBRE, CPS, 2010.

NEUMAN, C. Marcas famosas se envergonham de seus clientes pobres, diz pesquisa. 2014. Disponível em: < http://www.pragmatismopolitico.com.br/2014/02/marcas-famosas-se-envergonham-de-seus-clientes-pobres-dizpesquisa.html>. Acesso em: 15 out. 2014

PARENTE, J.; BARKI, E. Oportunidades na baixa renda. GV Executivo, v.4, n.1, p.33-37, 2005.

PRAHALAD, C.K. The fortune at the bottom of the pyramid: eradicating poverty through profits. New Jersey, USA: Pearson Education, 2006.

PRAHALAD, C.K.; HAMMOND, A. Serving the world's poor profitably. Harvard Business Review, v.80, n.9, p.4-11, 2002. PRAHALAD, C.K.; HART, S.L. The fortune at the bottom of the pyramid. Strategy and Business, v.26, p.1-14, 2002.

RATNER, C. Educating the low-income consumer: some viewpoints from an action program. Journal of Consumer Affairs, v.2, n.1, p.107-114, 1968.

ROCHA, A. Empresas e clientes: um ensaio sobre valores e relacionamentos no Brasil. São Paulo: Atlas, 2000.

ROCHA, A.R.; Araujo, F.; MOTTA, P.C. Atitudes de consumidores de baixa renda em relação às restrições de lazer. Revista Pensamento Contemporânea em Administração, v.8, n.1, p.142-163, 2014.

RUBIN, H.; RUBIN, I. Qualitative interviewing: the art of hearing data. 2.ed. Thousand Oaks: Sage, 2005.

SÁ, S. Empresas ainda têm preconceito com a baixa renda. 2011. Disponível em:

<http://exame.abril.com.br/marketing/noticias/empresas-ainda-tem-preconceito-com-a-baixa-renda>. Acesso em: 14 jun. 2014.

SALLES, F. Classe C: desejada, mas mal atendida. 2011. Disponível em:

http://www.sm.com.br/Editorias/Consumo/Classe-C\%3A-desejada,-mas-mal-atendida-12739.html. Acesso em 14 jun. 2014.

SECRETARIA DE ASSUNTOS ESTRATÉGICOS. Vozes da Classe Média - É ouvindo a população que se constroem políticas públicas adequadas. Brasília: Marco Zero, 2012.

STURDIVANT, F.; HANSELMAN, W. Discrimination in the marketplace: another dimension. Social Sciente Quarterly, v.52, n.3, p.625-630, 1971 .

STURDIVANT, F.; WILHELM, W. Poverty, minorities, and consumer exploitation. In: STURDIVANT, F. (ed.). The ghetto marketplace. New York: Free Press, 1969.

SUBRAHMANYAN, S.; GOMEZ-ARIAS, T. Integrated approach to understanding consumer behavior at the bottom of the pyramid. Journal of Consumer Marketing, v.25, n.7, p.402-412, 2008.

SUTTER, M.; PLUTARCO, F.; PARENTE, J. Apresentação no ponto de vendas: um estudo exploratório no varejo de moda popular. Análise, v.23, n.1, p.5-18, 2013.

TOYER, A. Consumer education and low-income families. Journal of Consumer Affairs, v.2, n.1, p.114-120, 1968.

WALSH, G. Disadvantaged consumers' experiences of marketplace discrimination in customer services. Journal of Marketing Management, v.25, n.1/2, p.143-169, 2009

WALSH, G.; MCGUIRE, D. Consumers' experiences of marketplace discrimination in services: a conceptual model of antecedents and customer outcomes. Advances in Consumer Research, v.34, p.278-279, 2007.

WOOD, V.; PITTA, D.; FRANZAK, F. Successful marketing by multinational firms to the bottom of the pyramid: connecting share of heart, global "umbrella brands", and responsible marketing. Journal of Consumer Marketing, v.25, n.7, p.419-429, 2008.

YAN, R.-H.; LOTZ, S. Taxonomy of the influence of other customers in consumer complaint behavior: a socialpsychological perspective. Journal of Consumer Satisfaction, Dissatisfaction and Complaining Behavior, v.22, p.107-126, 2009.

ZILBER, S.; SILVA, F. Investigação sobre a existência de inovações disruptivas das grandes empresas multinacionais para o mercado brasileiro de baixa renda. Production, v.23, n.2, p.286-293, 2013. 